\title{
Overnight soaking or boiling of "Matooke" to reduce potassium content for patients with chronic kidney disease: does it really work?
}

\author{
Asiimwe $\mathrm{J}^{1}$, ${ }^{*}$ Sembajwe $\mathrm{LF}^{2}$, Senoga $\mathrm{A}^{1}$, Bakiika $\mathrm{E}^{1}$, Muwonge $\mathrm{H}^{2}$, Kalyesubula $\mathrm{R}^{1,2}$
}

1. Department of Internal Medicine, School of Medicine, Makerere University College of Health Sciences, P. O. Box 7072, Kampala, Uganda

2. Department of Medical Physiology, School of Biomedical Sciences, Makerere University College of Health Sciences; P. O. Box 7072, Kampala, Uganda

\begin{abstract}
Background: There is an increase in number of patients with chronic kidney disease (CKD) in Uganda's health facilities looking for different options of preparing matooke (bananas), their staple food.

Objective: To establish and evaluate an effective method of removing potassium from bananas (matooke).

Methods: Bananas were sampled from 5markets in Kampala, Uganda. Deionized water was used to soak the bananas and the potassium concentration was determined using an atomic absorption spectrophotometer in both the bananas and water after soaking for varying time intervals. We also determined the potassium concentrations in the bananas and the water after boiling the bananas at 200 degrees Celsius at intervals of 10 minutes (for 60 minutes).

Results: The potassium concentration did not appear to change on soaking alone without boiling. However, on boiling, the concentration in the bananas decreased from about $1.4 \mathrm{ppm}$ to approx. $1 \mathrm{ppm}$ after $60 \mathrm{~min}$; yet the concentration of potassium released into deionized water increased steadily from $0.0 \mathrm{ppm}$ to about $1.2 \mathrm{ppm}$ after $60 \mathrm{~min}$ of boiling.

Conclusion: This study demonstrates that boiling the bananas is a more effective way of removing the potassium from bananas than simply soaking them.

Key words: Potassium, chronic kidney disease, soaking of bananas before cooking

African Health Sciences 2013; 13(3): 546 - 550 http:/ /dx.doi.org/10.4314/ahs.v13i3.2
\end{abstract}

\section{Introduction}

Chronic kidney disease (CKD) is on the increase in Sub-Saharan Africa, with some countries reporting prevalence as high as 36\% amongst high risk populations ${ }^{1}$. Management of CKD partly involves restriction of Potassium intake due to the anticipated danger of hyperkalemia that may result from either decreased renal function or an increased dietary intake ${ }^{2,3}$. The recommended daily intake of potassium among patients with $\mathrm{CKD}$ is $<4 \mathrm{~g} /$ day for stage 1 and stage 2 patients, and $<2.4 \mathrm{~g} /$ day for patients with stage 3 and 4 disease ${ }^{4}$.

Due to the feared risks of hyperkalemia, patients with CKD have been advised to avoid consumption, or eat in moderation foods found to contain high levels $(>400 \mathrm{mg} / 100 \mathrm{~g})$ of potassium ${ }^{3}$.

\footnotetext{
*Corresponding author:

Larry Fred Sembajwe

Department of Medical Physiology

School of Medicine, College of Health Sciences

Makerere University

P. O Box 7072, Kampala, Uganda

Email:1arryfeds@gmail.com

flsembajwe@chs.mak.ac.ug
}

Such foods include among others: Matooke (local name for bananas or plantain in Uganda), tubers e.g. potatoes and yams, grains e.g. wheat, and vegetables such as soya beans ${ }^{5}$.

This often leaves patients with CKD with fewer choices of locally available foods for nourishment and therefore puts them at a higher risk of malnutrition. In addition to lack of food choices and the ensuing chronic inflammation, patients with CKD usually vomit a lot and lack appetite which further worsens the malnutrition ${ }^{6}$. Studies among patients with CKD in India and Nigeria have reported a high incidence of malnutrition in this patient population ${ }^{7}$.

In the tropics, plantains are a major source of food and income ${ }^{8}$ with Uganda alone producing an estimated 10 million tonnes annually ${ }^{9}$. This accounts for about $15 \%$ of the total world plantain output ${ }^{9}$. Most of the matooke produced in Uganda are consumed locally with over 12 million people (about $40 \%$ of the population) depending on the crop as their staple food ${ }^{9}$. In addition, matooke is the commonly served food to patients admitted with CKD at the Mulago National Referral Hospital 
Renal Unit. Therefore, many of the patients with CKD continue to regularly eat matooke despite its potential risks. Though it has not been proven, there is some evidence to suggest that the potassium content of most vegetables can be decreased through a process of leaching which entails slicing and soaking of vegetables overnight in water, then draining and boiling the vegetables in new water ${ }^{10}$. In application of the above principle, patients with CKD are often told to soak the matooke in cold water for about 12 hours prior to cooking. This is aimed at removing the potassium from the intracellular compartments of the bananas ${ }^{11}$ so that the bananas have less potassium by the time of consumption.

The scientific basis and the optimal recommendations for this practice have never been evaluated and there is no sufficient evidence to suggest that this practice works efficiently.

This study was therefore conducted to establish the effectiveness of this intervention in the removal of potassium from the matooke as well as the optimal time taken for this to happen before it can be deemed safe for consumption by the patients with CKD. The results of this study will inform the scientific community on the effectiveness of the soaking methods in removing potassium from matooke as well as the optimal time and method for performing this intervention.

\section{Methods}

\section{Study setting \& procedures}

The matooke were collected from five different markets in Kampala city of Uganda in order to rule out any regional differences in the mineral content of the same species of plantain. The bananas were taken to the laboratory where they were peeled. Some matooke samples were soaked in cold deionized water after which their potassium content at was determined at different time intervals of; 2hours, 4 hours, 6 hours, 8 hours, 12 hours and 24 hours. The amount of potassium that diffused into the soak water was also determined. Other matooke samples were boiled at $200^{\circ} \mathrm{C}$ for the following intervals of; $10 \mathrm{~min}, 20 \mathrm{~min}, 30 \mathrm{~min}$,

$40 \mathrm{~min}, 50 \mathrm{~min}$ and $60 \mathrm{~min}$ using a temperature regulated hot plate in the laboratory. The amount of potassium that diffused into the boiling water, as well as that left in boiled matooke was determined at each of those time intervals.

The potassium content of either water or banana tissues, was analyzed and quantified using an atomic absorption spectrophotometer, which is found at the School of Science in Makerere University. A modified protocol for determining potassium concentration using an atomic absorption spectrophotometer was followed, as used elsewhere ${ }^{12}$. In our protocol, we used a grinder/ blender to homogenize the matooke for 5 minutes; we used $30 \mathrm{ml} / 1 \mathrm{gm}$ of nitric acid to decompose the matooke in order to pulverize the organic matter; and $2 \mathrm{ml} / 1 \mathrm{gm}$ of hydrogen peroxide was used to oxidize and remove organic materials present in the matooke by its "foaming" action. This was all done to ensure complete extraction of potassium from the bananas so that it can be accurately quantified. The concentration of potassium in the matooke or soak-water was then determined against stock standards for potassium.

\section{Data analysis}

The analysis was done according to the clusters (or markets where the bananas were obtained). The potassium concentration of the matooke was correlated and plotted against either/ or both the duration of soaking, and/ or the duration of boiling/cooking for each sample, using SPSS (version 17). We run Pearson's correlation, to establish strength of the relationship between the potassium concentration in matooke and the water at the different intervals of time during soaking and boiling.

\section{Ethical approval}

The research protocol was approved by the School of Biomedical Sciences- Research and Ethics committee in Makerere University.

\section{Results \\ Soaking the bananas}

On plotting a line graph to show the changes in the concentration of Potassium in water soaked with matooke samples over a time, we observed that the potassium levels rose from $2.2 \mathrm{ppm}$ at 2 hours to $4.00 \mathrm{ppm}$ after 6hours, increasing exponentially to $6.08 \mathrm{ppm}$ at 20 hours of soaking. We also observed that there was little effect, if any, of soaking on depletion of potassium from the intracellular compartments of the matooke because the levels of potassium in the matooke samples soaked in water remained constant throughout the 20 hour duration of soaking as shown in table $1 \&$ figure 1 . On soaking, it was also noted that the different layers of the matooke kept sloughing off leaving the inner layers firm and intact. 
When we run Pearson's correlation, to establish strength of the relationship between the potassium concentration in matooke and the water at the different intervals of time during soaking, we got the correlation 'r value' $=-0.479(\mathrm{p}$-value; 0.161$)$.
This is a negative correlation co-efficient but a weak one, indicating that though there may be a relationship between time of soaking of matooke and loss in potassium, the $\mathrm{K}+$ loss-time relation is quite non significant.

Table 1: Concentration of potassium in (matooke) \& water after soaking (ppm)

\begin{tabular}{lllllllllll}
\hline $\begin{array}{l}\text { Soaking } \\
\text { duration } \\
\text { Samples }\end{array}$ & 2hrs & 4hrs & $\mathbf{6 h r s}$ & $\mathbf{8 h r s}$ & $\mathbf{1 0 h r s}$ & $\mathbf{1 2 h r s}$ & $\mathbf{1 4 h \mathbf { h }}$ & $\mathbf{1 6 h r s}$ & $\mathbf{1 8 h r s}$ & 20hrs \\
\hline $\begin{array}{l}\text { Water } \\
\text { (av) }\end{array}$ & 2.2 & 3.6 & 4 & 3.24 & 3.72 & 4.08 & 4.48 & 5.18 & 5.82 & 6.08 \\
$\begin{array}{l}\text { Bananas } \\
\text { (av) }\end{array}$ & 1.32 & 1.18 & 1.274 & 1.238 & 1.256 & 1.326 & 1.28 & 1.21 & 1.24 & 1.196 \\
Total & 3.52 & 4.78 & 5.274 & 4.478 & 4.976 & 5.406 & 5.76 & 6.39 & 7.06 & 7.276 \\
\hline
\end{tabular}

$*_{\mathrm{av}}=$ average potassium concentration, $\mathrm{ppm}=$ parts per million

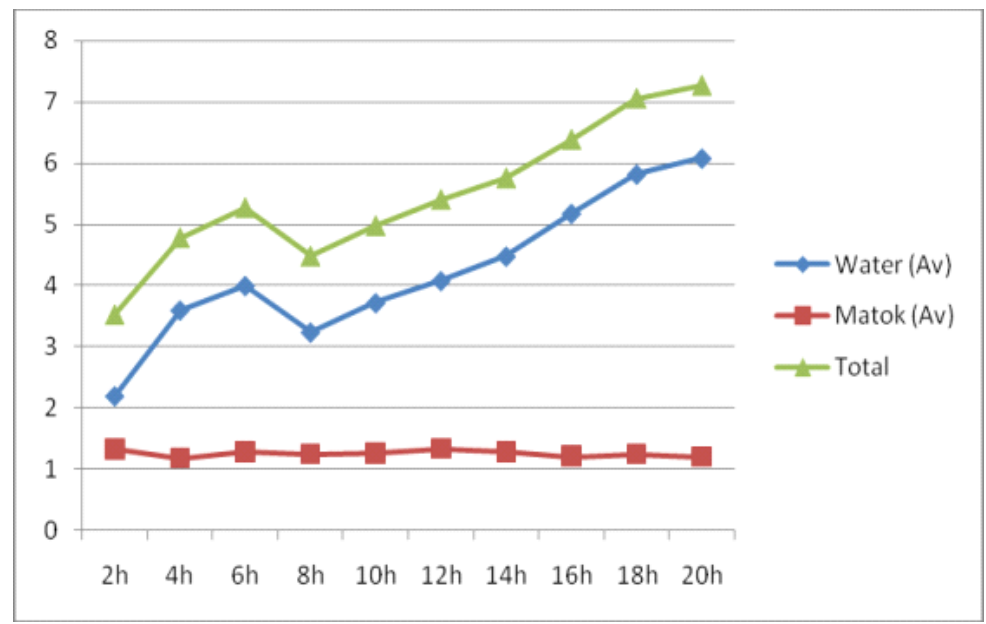

$*_{\mathrm{av}}=$ average potassium concentration

\section{Figure 1: Concentration of potassium in (matooke) \& water after soaking}

\section{On boiling the bananas}

The matooke from the different markets were boiled at 200 degrees centigrade which is about the average temperature attained from most open air charcoal stoves $^{15}$ commonly used in Uganda. On heating the samples of matooke collected at different intervals [of 10 minutes for $60 \mathrm{~min}$ ] against the time intervals for the different markets, we noted a progressive decrease in potassium concentrations in the matooke over time, during heating. At the same time, the potassium concentration in the water was noted to increase over time as heating progressed (table $2 \&$ figure 2). After 60 minutes of boiling the levels of potassium in the water changed very little while those in the matooke started increasing. 
Table 2: showing changes in potassium concentration of (matooke) \& water after boiling

\begin{tabular}{lllllll}
\hline \multicolumn{7}{l}{ Bananas/Water samples after boiling (ppm) } \\
\hline $\begin{array}{l}\text { Boiling } \\
\text { duration }\end{array}$ & 10min & 20min & 30min & 40min & 50min & 60min \\
\hline Bananas (av) & 1.35 & 1.24 & 1.1 & 1.04 & 0.96 & 0.88 \\
Water (av) & 0.08 & 0.3 & 0.46 & 0.58 & 0.78 & 0.94 \\
Total & 1.43 & 1.54 & 1.56 & 1.62 & 1.74 & 1.82 \\
\hline
\end{tabular}

$* \mathrm{Av}=$ average potassium concentration, $\mathrm{ppm}=$ parts per million

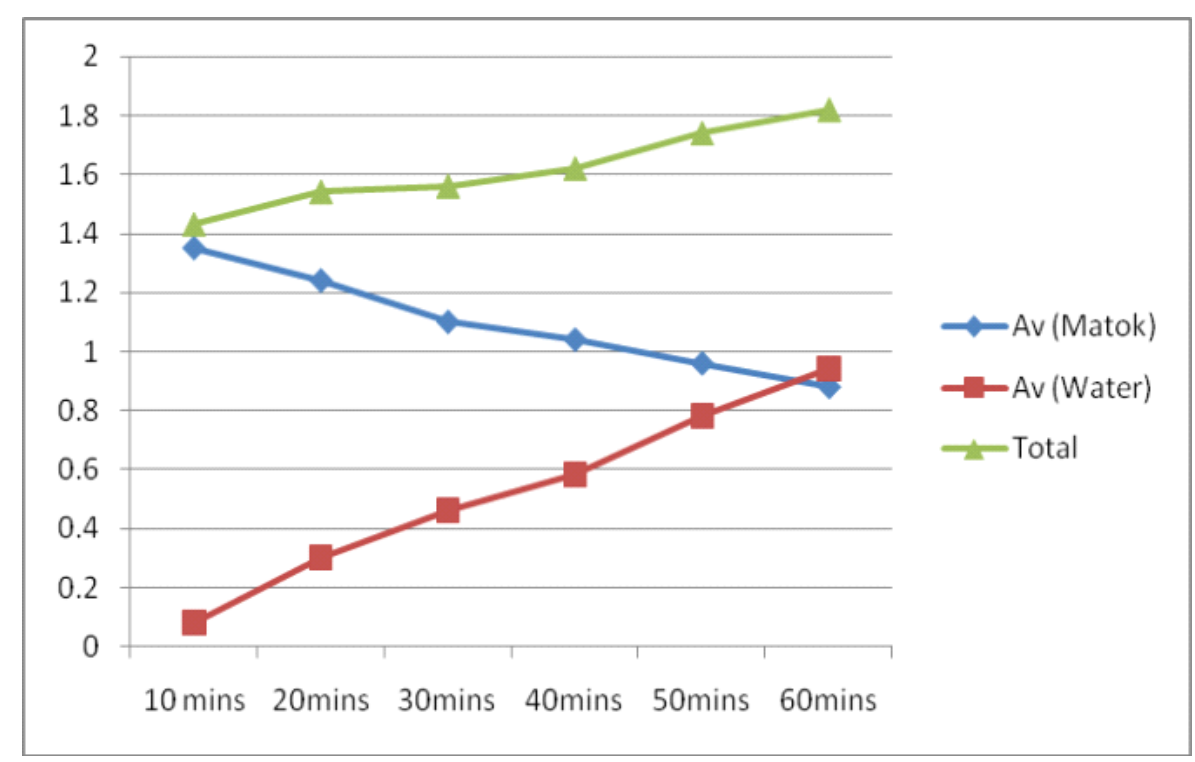

$*$ av $=$ average potassium concentration $\quad *($ matok $)=$ Matooke

Figure 2: Changes in potassium concentration of (Matooke) \& water after boiling

After running Pearson's on boiling, the $\mathrm{r}$ value $=-0.99$ ( $\mathrm{p}$-value $<0.001)$. The correlation coefficient obtained was a perfect negative that is -0.99 which is approximately one.

\section{Discussion}

This study has demonstrated that soaking matooke for 2-20 hours to remove potassium so that patients with chronic kidney disease can use it, is ineffective. This was a rather an unexpected finding as it was previously thought that the water would draw out the potassium from the matooke as the time of soaking increased as seen from previous evidence which suggested that soaking vegetables for a period of at least 12 hours in water caused leaching of potassium from the vegetables ${ }^{10}$. However, the lack of effectiveness of this method could probably be due to the fact that the matooke have different compartments (layers) of potassium as shown by observations made elsewhere ${ }^{13,16}$. In our study the different layers of the matooke kept peeling off into the water which could explain why the levels of potassium in the water increased despite constant levels in the matooke. Clearly, this shows that soaking matooke is not an effective way of removing potassium from them.

On boiling the matooke, the level of the potassium from the matooke correlated with that of the boiling water up to about 60 minutes. This negative correlation co-efficiency means that as boiling takes place, potassium loss also occurs at almost the same rate. The coefficient is negative because as the matooke lose potassium, it is gained by the water. So there is decrease in potassium concentrations in matooke and increase in potassium concentrations in the water, in which the matooke was being boiled. Cooking matooke at temperatures above $70^{\circ} \mathrm{C}$ leads to solubilization of pectin, a major component in the cell walls of banana cells ${ }^{14}$. This makes the cells more susceptible to rupture which also ultimately contributes to the dissolution of the middle lamella of the banana ${ }^{14}$, a layer that contains the highest level of potassium in the banana fruit ${ }^{13,16}$. This subsequently leads to release of potassium 
from the banana and hence the observed reduced potassium concentrations in the matooke after 60 minutes of cooking at $200^{\circ} \mathrm{C}$ in this study.

This study shows that boiling is effective in removing potassium concentrations from the intracellular compartments of the matooke and may be the preferred method of preparation for patients with kidney disease who still want to eat matooke.

Our study had some limitations as it did not evaluate the effect of boiling on the other micronutrients which have been found to be plenty in these matooke. We cannot therefore give comments on these other electrolytes. Other studies may look into this aspect as well. We also used temperatures of 200 degrees Celsius which may be on a higher side in an ordinary kitchen cooking environment in Uganda where people use mainly firewood or charcoal to cook their food.

\section{Conclusion}

Soaking matooke is not an effective way of removing potassium. Boiling matooke at temperatures of 200 degrees Celsius, for at least or more than 60 minutes, depending on the source of heating used, is an effective way of removing potassium. This method could be recommended for use by patients with chronic kidney disease and hyperkalaemia.

\section{Acknowledgements}

We thank the Departments of; Internal Medicine of Makerere University and Medical Physiology in Makerere College of Health Sciences for providing technical support to the study. We are also very grateful for the funding received from MEPIMESAU consortium which made this research possible.

\section{References}

1. Sumaili E, Cohen E, Zinga C, Krzesinski J-M, Pakasa N, Nseka N: High prevalence of undiagnosed chronic kidney disease among atrisk population in Kinshasa, the Democratic Republic of Congo. BMC Nephrology 2009; 10(1):18.

2. Adrogué HJ, NE M: "Changes in plasma potassium concentration during acute acid-base disturbances". Am J Med 1981; 71(3):456-467.

3. Ash S, Campbell K, MacLaughlin H, McCoy E, Chan M, Anderson K, Corke K, Dumont R, Lloyd L, Meade A et al: Evidence based practice guidelines for the nutritional management of chronic kidney disease. Nutrition \& Dietetics 2006;
63:S33-S45.

4. Recommendations summary: Chronic kidney disease-potassium [http:// w w w a d a evidencelibrary.com/ template.cfm?template $=$ guide_summary\&key $=2779 \&$ hig hlight $=\mathrm{CKD} \&$ home $=1]$

5. Plantain [http://en.wikipedia.org/wiki/ Plantain]

6. Prakash J, Raja R, Mishra RN, Vohra R, Sharma N, Wani IA, Parekh A: High prevalence of malnutrition and inflammation in undialyzed patients with chronic renal failure in developing countries: a single center experience from eastern India. Ren Fail 2007, 29(7):811-816.

7. Agaba EI, Agaba PA: Prevalence of malnutrition in Nigerians with chronic renal failure. Int Urol Nephrol 2004, 36(1):89-93.

8. Swennen R, Vuylsteke D, Ortiz R: Phenotypic Diversity and Patterns of Variation in West and Central African Plantains ( \&lt;i\&gt;Musa Spp., AAB group Musaceae). Economic Botany 1995, 49(3):320-327.

9. Karamura E B: The strategic importance of bananas and plantain in Uganda. In: Proceedings of a Research Co-ordination Meeting for Biological and Integrated Control of Highland Banana Pests and Diseases in Africa, Cotonou, 12-14 November 1991: 1993; Ibadan, Ghana: International Institute of Tropical Agriculture; 1993: 384-387.

10. U.S. DEPARTMENT OF HEALTH AND HUMAN SERVICES: Chronic Kidney Disease and Diet: Assessment, Management, and Treatment. In: An overview guide on treating CKD patients who are not on dialysis Overview guide for Dieticians. September 2011.

11. Forster MP, Rodríguez Rodríguez E, Martín JD, C. DR: Statistical differentiation of bananas according to their mineral composition. .

12. F. Ismail, M.R. Anjum, A.N. Mamon, Kazi TG: Trace metal contents of vegetables and fruits of Hyderabad Retail Market. Pakistan Journal of Nutrition 2011; 10(4):365-372.

13. Eglen D E. Peeling away misconception. MLO Med Lab Obs. 2009 May; 41(5): 6.

14. Qi B, Moore KG, Orchard J: Effect of cooking on banana and plantain texture. $J$ Agric Food Chem 2000; 48(9):4221-4226.

15. http://www.bbqrecipesecrets.com/ temperature.html. accessed on 19th/11/ 2012.

16. Avallone S, Rojas-Gonzalez JA, Trystram $G$, Bohuon P. Thermal sensitivity of some plantain micronutrients during deep-fat frying. J Food Sci. 2009; 74(5):C339-47.

African Health Sciences Vol 13 Issue 3 September 2013 